PHYSICS REVIEW

A.B. Smith

W.P. Dillon

R. Gould

M. Wintermark

\section{Radiation Dose-Reduction Strategies for Neuroradiology CT Protocols}

\begin{abstract}
SUMMARY: Within the past 2 decades, the number of CT examinations performed has increased almost 10-fold. This is in large part due to advances in multidetector-row CT technology, which now allows faster image acquisition and improved isotropic imaging. The increased use, along with multidetector technique, has led to a significantly increased radiation dose to the patient from CT studies. This places increased responsibility on the radiologist to ensure that CT examinations are indicated and that the "as low as reasonably achievable" concept is adhered to. Neuroradiologists are familiar with factors that affect patient dose such as pitch, milliamperes, kilovolt peak (kVp), collimation, but with increasing attention being given to dose reduction, they are looking for additional ways to further reduce the radiation associated with their CT protocols. In response to increasing concern, CT manufacturers have developed dose-reduction tools, such as dose modulation, in which the tube current is adjusted along with the CT acquisition, according to patient's attenuation. This review will describe the available techniques for reducing dose associated with neuroradiologic CT imaging protocols.
\end{abstract}

T he increase in the number of CT studies in the United States and Europe ${ }^{1,2}$ that followed the introduction of multidetector-row technology has led to a significant increase in the radiation dose related to $\mathrm{CT}$ scanning. ${ }^{3-6} \mathrm{CT}$ scanning comprises approximately $15 \%$ of radiologic examinations but represents the largest single source of medical radiation exposure, accounting for up to $70 \%$ of the radiation dose to patients. ${ }^{7}$ Patients are becoming more aware of the radiation dose related to CT scanning due to increasing coverage in the lay press. ${ }^{8}$ The radiation risk to children is of particular concern; the estimated lifetime cancer risk for a 1-year-old child from the radiation exposure of a head CT is $0.07 \% .^{9}$

The potential health risks associated with radiation have placed increasing pressure on the radiology community to ensure that CT imaging protocols are optimized for diagnostic image quality at the lowest radiation dose possible ("as low as reasonably achievable"). Because the latest generation of CT scanners automatically records the CT dose for each study and archives this as part of the patient's permanent medical record, exaggerated delays in implementing dose-reduction strategies may also have medical-legal implications. The purpose of this review is to discuss available methods to achieve dose reduction for neuroradiology CT protocols while preserving the diagnostic quality of imaging studies.

\section{CT-Associated Radiation-Dose Measurement}

In 2001, in response to the growing concern over CT-associated radiation dose, the US Food and Drug Administration published guidelines to address this issue, especially in pediatric patients and in the small-adult population. These guidelines give recommendations on how to optimize CT protocols and encourage the elimination of inappropriate referrals for CT as well as the reduction of the number of unnecessary repeat examinations. ${ }^{10}$ Along the same lines, the American

Received July 19, 2007; accepted August 7

From the Department of Radiology, Neuroradiology Section, University of California, San Francisco, Calif.

Please address correspondence to Max Wintermark, MD, Department of Radiology, Neuroradiology Section, University of California, San Francisco, 505 Parnassus Ave, Box 0628, San Francisco, CA 94143-0628; e-mail: Max.Wintermark@radiology.ucsf.edu

DOI 10.3174/ajnr.A0814
College of Radiology (ACR) established a voluntary CT accreditation program. Institutions that apply are invited to complete a series of protocols and to submit patient and phantom images, along with dose measurements, to show that they abide by ACR dose recommendations. ${ }^{11}$

To understand the radiation dose a patient receives for a particular scan, one must have knowledge of the methods of dose measurement. Multiple dose descriptors have been used in the past. Currently, the Computed Tomography Dose In$\operatorname{dex}$ (CTDI), along with its variants, and the Dose Length Product (DLP) are the standard parameters used to describe CT-associated radiation dose.

Different versions of the CTDI have been used. Historically, the CTDI was initially defined as the radiation dose measured from 14 contiguous sections and normalized to beam width and took into account the radiation dose delivered both within and beyond the scanning volume. Indeed, scattered radiation, divergence of radiation beam, and limits in efficiency of beam collimation result in the radiation delivered during a CT scan not fully contained within the scanning volume. The CTDI ${ }_{100}$ was developed to address the limitation of the 14-section model and allowed calculation of the index for $100 \mathrm{~mm}$ along the length of a pencil ionization chamber. The weighted CTDI $\left(\mathrm{CTDI}_{\mathrm{w}}\right)$ was subsequently developed to overcome the limitations of dependency on position within the scanning plane and represents a dose index that provides a weighted average of central and peripheral contributions within the scanning plane. The $\mathrm{CTDI}_{\mathrm{w}}$ describes the average dose throughout a 100-mm-diameter circular phantom, adding up the central dose weighted by a one-third factor and the peripheral dose weighted by a two-thirds factor. The most recent and presently used version is the volumetric CTDI $\left(\mathrm{CTDI}_{\mathrm{vol}}\right)$, which was introduced to take into account the pitch of helical acquisition. The $\mathrm{CTDI}_{\mathrm{vol}}$ represents the average dose delivered within the reconstructed section and is calculated as the CTDI ${ }_{\mathrm{w}}$ divided by the pitch. ${ }^{12,13}$

The DLP is the CTDI ${ }_{\mathrm{vol}}$ multiplied by the scanning length expressed in centimeters. It gives an indication of the energy imparted to organs and can be used to assess overall radiation burden associated with a CT study. CT scanners now routinely record the $\mathrm{CTDI}_{\mathrm{vol}}$, and, in some cases, the DLP. Although the 
$\mathrm{CTDI}_{\mathrm{vol}}$ is not the dose to a specific patient, it is an index of the average radiation dose from the different CT series. ${ }^{1,12,13}$

The ACR guidelines set reference values for CTDI on the basis of reports from the American Association of Physicists in Medicine and the International Commission on Radiologic Protection. For instance, for a head CT in an adult patient, the recommended $\mathrm{CTDI}_{\mathrm{w}}$ is $60 \mathrm{mGy}$. If this dose is exceeded, measures need to be taken to reduce the patient dose. ${ }^{11}$

\section{CT Acquisition Parameters and Dose Reduction}

The setting of CT parameters such as tube current, tube rotation time, peak voltage, pitch, and collimation is a major contributor to the radiation dose received during a CT study. Typically, if one of these parameters is decreased, another needs to be increased to maintain image quality. Developing methods for dose reduction for CT protocols consequently takes a team effort of physicist, radiologist, and technician to determine the best compromise between diagnostic image quality and radiation dose. $^{14}$

The initial approach to optimizing dose is to determine what information is desired from an examination and the associated minimum level of contrast to noise that is acceptable for diagnostic purposes. If lesser contrast is required and greater noise can be tolerated, then a lower tube current (and lower milliamperes) should be used. Tube current is directly proportional to dose; therefore, tube current reduction will result in a lower dose but at a cost of increased noise, which is increased by $1 / \sqrt{ }(\mathrm{mA})$. Gantry rotation time also has a similar effect on radiation dosage, and reducing the gantry rotation time by half leads to the same results in dose as reducing the milliampere by half. This can be advantageous when a quicker acquisition is needed, for instance in unstable patients. ${ }^{14}$ Of note, decreasing the gantry rotation time is not a panacea because it may unfavorably impact on the spatial resolution. Indeed, as explained previously, decreasing the gantry rotation time has to be compensated by an increase in milliamperes to maintain the milliamperes at a constant level. Increasing the milliamperes above a certain value (300-350) will typically result in the CT scanner switching from the small to the large focal spot, resulting in decreased spatial resolution.

Decreasing the peak voltage can also result in a lower dose (proportional to the square of the tube voltage change) as long as the tube current is not increased to compensate. ${ }^{14}$ However, decreasing the peak voltage often reduces significantly $\mathrm{x}$-ray penetration, especially through bony structures such as the skull, and requires a significant increase in milliamperes to counterbalance this reduction in $\mathrm{x}$-ray penetration, resulting in an overall increased radiation dose. For this reason, it is preferable to use a high kilovolt peak $(\mathrm{kVp})(120$ or $140 \mathrm{kVp})$ technique, except in specific applications such as perfusion $\mathrm{CT}$, in which $80 \mathrm{kVp}$ is typically used combined with low milliamperes (typically 100) because this combination affords increased contrast (closer to the K-edge for iodine), whereas radiation dose is reduced. ${ }^{15}$

Helical pitch, which describes the advancement of the scanning plane through the patient's body, is inversely related to dose when all other factors are held constant. A higher pitch results in a decreased amount of time that an anatomic part is exposed to radiation. By increasing the pitch, the dose to the patient is decreased; however, volume averaging is increased due to an increase in effective section thickness, and spatial resolution along the $\mathrm{z}$-axis is slightly decreased. Lower pitch results in higher image quality but longer scanning time and higher patient dose. ${ }^{1}$ For practically all our neuroradiology CT studies, a pitch slightly inferior to 1 is used. For our CTAs of the cervical and intracranial arteries, a pitch slightly superior to 1 (at least on our 4-, 8-, and 16-section CT scanners) allows further reduction of the radiation dose while maintaining an acceptable image quality. For CTA examinations that focus on intracranial vessels for aneurysm screening, a pitch slightly inferior to 1 is optimal to improve spatial resolution along the $\mathrm{z}$-axis and to acquire as close to isotropic datasets as possible for improved multiplanar reconstructions.

On multidetector CT scanners, the radiation profile width is influenced by the collimation. An "overbeaming" effect results from the x-ray beam extending beyond the edge of detector rows, exposing the patient to greater radiation dose. Thicker collimation decreases this effect, whereas a narrower degree of collimation results in a greater penumbral effect, more overbeaming, and, therefore, a higher radiation dose to the patient. The $\mathrm{CTDI}_{\mathrm{w}}$ can increase by as much as 55\% in a head phantom when narrower beam collimation is used. ${ }^{12}$ Prepatient tracking is a method introduced by the manufacturers to decrease the effect of overbeaming. With this technique, overbeaming is reduced by measurement of the beam position every few milliseconds and repositioning of the source aperture to keep a narrow beam focused on the detector. ${ }^{1}$

As a general rule of the thumb, collimation should be set to acquire images as thin as one may be interested (now or later), but realizing the potential cost in dose. Typically, thin collimation $(0.625 \mathrm{~mm})$ and thin (and overlapped) reconstructions $(0.625 \mathrm{~mm})$ are used for those techniques that require high spatial detail, such as intracranial CTA or CT of the cervical spine, where the highest spatial resolution is sought to detect small aneurysms or subtle fractures. At the other end of the spectrum, thin collimation $(0.625 \mathrm{~mm})$ and thicker reconstruction (and again overlapped) images $(2.5 \mathrm{~mm}$ ) may be best used for CT studies of the lumbar spine. This "acquire thin and view thick" strategy is very dose-efficient because whereas the display images will be thick, low acquisition parameters can be used for the acquisition. The source images will be noisy, but the thick images used for review will not; and the source images with higher spatial resolution will be available if required to interpret an unresolved finding on the thick review images and as source images for 2D and 3D reformats. This "acquire thin and review thick" approach is not only efficient in terms of radiation dose but also improves workflow because fewer images need to be reviewed.

\section{CT Dose Modulation}

Many of the dose-reduction strategies described previously result in a trade-off of image quality. For example, if tube current or voltage is reduced, the radiation dose is reduced, but so is image quality. CT manufacturers have tried to come up with new technologies that can reduce dose without significantly compromising imaging quality. One of these techniques is dose modulation.

Dose modulation is a technique by which the CT scanner modifies the tube current in response to the patient's attenu- 
ation, to maintain the same image quality for the least possible tube current. Dose modulation can be performed in the $\mathrm{z}$-axis where tube current changes along the length of the patient, in the xy-plane (angular modification), or can be a combination of the 2 (xyz-dose modulation). Recent studies demonstrated that dose modulation is capable of providing a reduction in radiation dose without significant image compromise, ${ }^{16-20}$ including for neuroradiology CT protocols, where up to $60 \%$ dose reduction was achieved for noncontrast CT of the brain in adult and pediatric patients; for CT studies of the cervical spine; and for CTA studies. ${ }^{21}$

Implementation of dose modulation requires a team effort between radiologists, technicians, and physicists, who have to select a preset noise index (NI) that describes the level of noise acceptable to the radiologist for a given CT examination. The CT scanner then automatically selects, within a preset range, the tube current (milliampere) required to maintain the level of noise under the noise index, taking into consideration the patient's attenuation. Identification of optimal signal intensity-to-noise ratio for each type of CT protocol requires fine-tuning to lower the milliamperes as much as possible while preserving image quality. When we transitioned to dose modulation, we initially set the NI at a low value (as recommended by the manufacturer) and progressively increased it until the image quality was deemed insufficient. This decision was a consensus decision by the 9 faculty members of our neuroradiology section.

\section{Image Postprocessing as an Additional Consideration for Dose Reduction}

Isotropic resolution afforded by modern multidetector row CT scanners allows high-quality image reconstruction and can help diminish the number of scans needed, thus reducing patient dose. Previously, we used to acquire both axial and direct coronal images for our sinus CT studies. We now acquire the images in helical mode in the axial plane with a section thickness of $0.625 \mathrm{~mm}$ and reconstruct them in the coronal plane. Our ear, nose, and throat surgeons have been satisfied with the diagnostic quality, and the patients undergo 1 scanning instead of 2. Likewise, we reformat our CT angiograms into the coronal and sagittal planes, and we reconstruct the axial planes into a thicker section thickness to decrease the noise within the images. If questions arise concerning more subtle findings, we are able to use the thinner section thickness to help differentiate the presence or absence of an abnormality, such as an aneurysm. Maximal image projections can be used for evaluation of structures such as vessels, and 3D reformations can further help define structures.

Other postprocessing techniques such as retroprojection filters and noise-reduction filters have been introduced by manufacturers to assist in improving image quality for already-acquired images. ${ }^{22,23}$ Their usefulness in terms of neuroradiology CT protocols is mainly for CTA of the cervical vessels at the level of the shoulders and whenever there is metallic hardware that is responsible for significant beam-hardening effect.

\section{Conclusion}

CT scanners are a major contributor to the radiation dose received in radiology departments. There are many strategies available to reduce the radiation dose associated with neuroradiology CT protocols. Some of these strategies involve changes in the acquisition parameters $(\mathrm{kVp}$, gantry rotation time, milliampere, pitch). Such strategies, however, always involve a compromise between image quality and radiation dose. The optimal compromise can usually be achieved by applying simple rules of thumb (such as "acquire thin and review thick"). More recently, CT manufacturers have introduced techniques of dose reduction, such as dose modulation, which result in a decrease in dose to patients without significant image compromise. As such, we recommend the systematic implementation of dose modulation for all neuroradiology CT protocols.

\section{Appendix}

In this appendix are listed our neuroradiology CT protocols for our 64-section CT scanners (Lightspeed VCT; GE Healthcare, Milwaukee, Wis). These are to serve as an illustration of

\begin{tabular}{|c|c|c|c|c|c|c|c|c|c|c|c|c|c|c|c|c|}
\hline \multicolumn{17}{|c|}{ Standard CT studies of the brain } \\
\hline \multirow[b]{2}{*}{ Series } & \multirow{2}{*}{$\begin{array}{l}\text { Scan } \\
\text { Type }\end{array}$} & \multirow{2}{*}{$\begin{array}{c}\text { Detector } \\
\text { Configuration }\end{array}$} & \multirow[b]{2}{*}{ Pitch } & \multirow[b]{2}{*}{ Speed } & \multirow{2}{*}{$\begin{array}{l}\text { FOV } \\
(\mathrm{cm})\end{array}$} & \multirow{2}{*}{$\mathrm{kVp}$} & \multicolumn{3}{|c|}{ Auto $\mathrm{mA}$} & \multirow{2}{*}{$\begin{array}{l}\text { Rotation } \\
\text { Time }\end{array}$} & \multirow{2}{*}{$\begin{array}{l}\text { Section } \\
\text { Thickness }\end{array}$} & \multirow{2}{*}{$\begin{array}{l}\text { Reconstruction } \\
\text { Interval }\end{array}$} & \multirow{2}{*}{$\begin{array}{l}\text { Prep } \\
\text { Group }\end{array}$} & \multirow[b]{2}{*}{ Amount } & \multirow{2}{*}{$\begin{array}{l}\text { Saline } \\
\text { Flush }\end{array}$} & \multirow[b]{2}{*}{ Rate } \\
\hline & & & & & & & Min & Max & $\mathrm{NI}$ & & & & & & & \\
\hline NCT & Helical & $32 \times 0.625$ & $0.969: 1$ & 19.37 & 22 & 120 & 100 & 350 & 4 & 1 & 2.5 & 2.5 & - & - & - & - \\
\hline СЕCT & Helical & $32 \times 0.625$ & $0.969: 1$ & 19.37 & 22 & 120 & 100 & 350 & 4 & 1 & 2.5 & 2.5 & 120 & 70 & 25 & 1 \\
\hline
\end{tabular}

Note:-NCT indicates noncontrast CT; -, not applicable; Min, minimum; Max, maximum; CECT, contrast-enhanced CT.

\begin{tabular}{|c|c|c|c|c|c|c|c|c|c|c|c|c|c|c|c|c|}
\hline \multicolumn{17}{|c|}{ Stroke CT protocol } \\
\hline \multirow[b]{2}{*}{ Series $^{a}$} & \multirow{2}{*}{$\begin{array}{l}\text { Scan } \\
\text { Type }\end{array}$} & \multirow{2}{*}{$\begin{array}{c}\text { Detector } \\
\text { Configuration } \\
\end{array}$} & \multirow[b]{2}{*}{ Pitch } & \multirow[b]{2}{*}{ Speed } & \multirow{2}{*}{$\begin{array}{l}\text { FOV } \\
(\mathrm{cm})\end{array}$} & \multirow[b]{2}{*}{$k V p$} & \multicolumn{3}{|c|}{ Auto $\mathrm{mA}$} & \multirow{2}{*}{$\begin{array}{l}\text { Rotation } \\
\text { Time }\end{array}$} & \multirow{2}{*}{$\begin{array}{l}\text { Section } \\
\text { Thickness }\end{array}$} & \multirow{2}{*}{$\begin{array}{l}\text { Reconstruction } \\
\text { Interval }\end{array}$} & \multirow{2}{*}{$\begin{array}{l}\text { Prep } \\
\text { Group }\end{array}$} & \multirow{2}{*}{\multicolumn{2}{|c|}{$\begin{array}{l}\text { Saline } \\
\text { Flush }\end{array}$}} & \multirow[b]{2}{*}{ Rate } \\
\hline & & & & & & & Min & Max & $\mathrm{NI}$ & & & & & & & \\
\hline NCT & Helical & $32 \times 0.625$ & $0.969: 1$ & 19.37 & 22 & 120 & 100 & 350 & 4 & 1 & 2.5 & 2.5 & - & - & - & - \\
\hline PCT1 & Cine & $8 \times 5$ & - & - & 22 & 80 & & 00 & - & 1 & 5 & 5 & 7 & 40 & 25 & 5 \\
\hline PCT2 & Cine & $8 \times 5$ & - & - & 22 & 80 & & 00 & - & 1 & 5 & 5 & 7 & 40 & 25 & 5 \\
\hline CTA & Helical & $64 \times 0.625$ & $0.984: 1$ & 98.42 & 25 & 120 & 200 & 400 & 12 & 0.4 & 1.25 & 1 & From PCT & 70 & 25 & 5 \\
\hline СЕСТ & Helical & $32 \times 0.625$ & 0.969:1 & 19.37 & 22 & 120 & 100 & 350 & 4 & 1 & 2.5 & 2.5 & 120 & - & - & - \\
\hline
\end{tabular}

Note:-NCT indicates noncontrast CT; Min, minimum; Max, maximum; PCT, perfusion CT; -, not applicable; CTA, CT angiography; CECT, contrast-enhanced CT

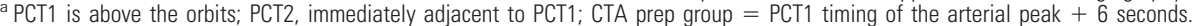


Subarachnoid hemorrhage and venous thrombosis CT protocols ${ }^{\mathrm{a}}$

\begin{tabular}{|c|c|c|c|c|c|c|c|c|c|c|c|c|c|c|c|c|}
\hline \multirow[b]{2}{*}{ Series $^{b}$} & \multirow{2}{*}{$\begin{array}{l}\text { Scan } \\
\text { Type }\end{array}$} & \multirow{2}{*}{$\begin{array}{c}\text { Detector } \\
\text { Configuration }\end{array}$} & \multirow[b]{2}{*}{ Pitch } & \multirow[b]{2}{*}{ Speed } & \multirow{2}{*}{$\begin{array}{l}\text { FOV } \\
(\mathrm{cm})\end{array}$} & \multirow[b]{2}{*}{$k V p$} & \multicolumn{3}{|c|}{ Auto $\mathrm{mA}$} & \multirow{2}{*}{$\begin{array}{l}\text { Rotation } \\
\text { Time }\end{array}$} & \multirow{2}{*}{$\begin{array}{c}\text { Section } \\
\text { Thickness }\end{array}$} & \multirow{2}{*}{$\begin{array}{c}\text { Reconstruction } \\
\text { Interval }\end{array}$} & \multirow{2}{*}{$\begin{array}{l}\text { Prep } \\
\text { Group }\end{array}$} & \multirow[b]{2}{*}{ Amount } & \multirow{2}{*}{$\begin{array}{l}\text { Saline } \\
\text { Flush }\end{array}$} & \multirow[b]{2}{*}{ Rate } \\
\hline & & & & & & & Min & Max & $\mathrm{NI}$ & & & & & & & \\
\hline$\overline{\mathrm{NCT}}$ & Helical & $32 \times 0.625$ & 0.969:1 & 19.37 & 22 & 120 & 100 & 350 & 4 & 1 & 2.5 & 2.5 & - & - & - & - \\
\hline PCT1 & Cine & $8 \times 5$ & - & - & 22 & 80 & \multicolumn{2}{|c|}{100} & - & 1 & 5 & 5 & 7 & 40 & 25 & 5 \\
\hline РCT2 & Cine & $8 \times 5$ & - & - & 22 & 80 & \multicolumn{2}{|c|}{100} & - & 1 & 5 & 5 & 7 & 40 & 25 & 5 \\
\hline CTA & Helical & $64 \times 0.625$ & 0.984:1 & 98.42 & 25 & 120 & 200 & 400 & 12 & 0.4 & 0.625 & 0.5 & From PCT & 70 & 25 & 5 \\
\hline CECT & Helical & $32 \times 0.625$ & 0.969:1 & 19.37 & 22 & 120 & 100 & 350 & 4 & 1 & 2.5 & 2.5 & 120 & - & - & - \\
\hline
\end{tabular}

Note:-Min, minimum; Max, maximum; NCT indicates noncontrast CT; PCT, perfusion CT; -, not applicable; CTA, CT angiography; CECT, contrast-enhanced CT.

${ }^{\mathrm{a}}$ For subarachnoid hemorrhage CT Protocol: CTA prep group = PCT1 timing of the arterial peak +7 seconds for venous thrombosis CT protocol: CTA prep group $=$ PCT1 timing of the arterial peak +10 seconds.

b PCT1, above the orbits; PCT2, immediately adjacent to PCT1.

\section{Orbit, face, and sinus CT protocols}

\begin{tabular}{|c|c|c|c|c|c|c|c|c|c|c|c|c|c|c|c|c|}
\hline \multirow[b]{2}{*}{ Series } & \multirow{2}{*}{$\begin{array}{l}\text { Scan } \\
\text { Type }\end{array}$} & \multirow{2}{*}{$\begin{array}{c}\text { Detector } \\
\text { Configuration }\end{array}$} & \multirow[b]{2}{*}{ Pitch } & \multirow[b]{2}{*}{ Speed } & \multirow{2}{*}{$\begin{array}{l}\text { FOV } \\
(\mathrm{cm})\end{array}$} & \multirow[b]{2}{*}{$k V p$} & \multicolumn{3}{|c|}{ Auto $\mathrm{mA}$} & \multirow{2}{*}{$\begin{array}{c}\text { Rotation } \\
\text { Time }\end{array}$} & \multirow{2}{*}{$\begin{array}{c}\text { Section } \\
\text { Thickness }\end{array}$} & \multirow{2}{*}{$\begin{array}{l}\text { Reconstruction } \\
\text { Interval }\end{array}$} & \multirow{2}{*}{$\begin{array}{l}\text { Prep } \\
\text { Group }\end{array}$} & \multirow{2}{*}{\multicolumn{2}{|c|}{$\begin{array}{l}\text { Saline } \\
\text { Flush }\end{array}$}} & \multirow[b]{2}{*}{ Rate } \\
\hline & & & & & & & Min & Max & $\mathrm{NI}$ & & & & & & & \\
\hline & Helical & $64 \times 0.625$ & $0.984: 1$ & 49.21 & 18 & 120 & 100 & 200 & 12 & 0.8 & 1.25 & 1 & - & - & - & - \\
\hline
\end{tabular}

Note:-Min, minimum; Max, maximum; -, not applicable.

\begin{tabular}{|c|c|c|c|c|c|c|c|c|c|c|c|c|c|c|c|c|}
\hline \multicolumn{17}{|c|}{ Temporal bone CT protocol } \\
\hline \multirow[b]{2}{*}{ Series } & \multirow{2}{*}{$\begin{array}{l}\text { Scan } \\
\text { Type }\end{array}$} & \multirow{2}{*}{$\begin{array}{c}\text { Detector } \\
\text { Configuration }\end{array}$} & \multirow[b]{2}{*}{ Pitch } & \multirow[b]{2}{*}{ Speed } & \multirow{2}{*}{$\begin{array}{l}\text { FOV } \\
(\mathrm{cm})\end{array}$} & \multirow[b]{2}{*}{$k V p$} & \multicolumn{3}{|c|}{ Auto $\mathrm{mA}$} & \multirow{2}{*}{$\begin{array}{l}\text { Rotation } \\
\text { Time }\end{array}$} & \multirow{2}{*}{$\begin{array}{l}\text { Section } \\
\text { Thickness }\end{array}$} & \multirow{2}{*}{$\begin{array}{c}\text { Reconstruction } \\
\text { Interval }\end{array}$} & \multirow{2}{*}{$\begin{array}{l}\text { Prep } \\
\text { Group }\end{array}$} & \multirow[b]{2}{*}{ Amount } & \multirow{2}{*}{$\begin{array}{l}\text { Saline } \\
\text { Flush }\end{array}$} & \multirow[b]{2}{*}{ Rate } \\
\hline & & & & & & & Min & Max & $\mathrm{NI}$ & & & & & & & \\
\hline & Helical & $64 \times 0.625$ & $0.984: 1$ & 49.21 & 20 & 120 & 100 & 200 & 9 & 0.8 & 0.625 & 0.5 & - & - & - & - \\
\hline
\end{tabular}

Note:-Min, minimum; Max, maximum; -, not applicable.

\begin{tabular}{|c|c|c|c|c|c|c|c|c|c|c|c|c|c|c|c|c|}
\hline \multicolumn{17}{|c|}{ Neck CT protocol } \\
\hline \multirow{3}{*}{ Series } & \multirow{2}{*}{$\begin{array}{l}\text { Scan } \\
\text { Type }\end{array}$} & \multirow{2}{*}{$\begin{array}{c}\text { Detector } \\
\text { Configuration }\end{array}$} & \multirow[b]{2}{*}{ Pitch } & \multirow[b]{2}{*}{ Speed } & \multirow{2}{*}{$\begin{array}{l}\text { FOV } \\
(\mathrm{cm})\end{array}$} & \multirow{2}{*}{$k V p$} & \multicolumn{3}{|c|}{ Auto $\mathrm{mA}$} & \multirow{2}{*}{$\begin{array}{c}\text { Rotation } \\
\text { Time }\end{array}$} & \multirow{2}{*}{$\begin{array}{l}\text { Section } \\
\text { Thickness }\end{array}$} & \multirow{2}{*}{$\begin{array}{l}\text { Reconstruction } \\
\text { Interval }\end{array}$} & \multirow{2}{*}{$\begin{array}{l}\text { Prep } \\
\text { Group }\end{array}$} & \multirow{2}{*}{\multicolumn{2}{|c|}{$\begin{array}{c}\text { Saline } \\
\text { Flush }\end{array}$}} & \multirow[b]{2}{*}{ Rate } \\
\hline & & & & & & & Min & Max & $\mathrm{NI}$ & & & & & & & \\
\hline & Helical & $64 \times 0.625$ & $0.984: 1$ & 49.21 & 18 & 120 & 100 & 200 & 6 & 0.8 & 2.5 & 2 & 60 & 100 & 25 & 2 \\
\hline
\end{tabular}

Note:-Min, minimum; Max, maximum.

\begin{tabular}{|c|c|c|c|c|c|c|c|c|c|c|c|c|c|c|c|c|}
\hline \multicolumn{17}{|c|}{ Cervical spine CT protocol } \\
\hline \multirow[b]{2}{*}{ Series } & \multirow{2}{*}{$\begin{array}{l}\text { Scan } \\
\text { Type }\end{array}$} & \multirow{2}{*}{$\begin{array}{c}\text { Detector } \\
\text { Configuration } \\
\end{array}$} & \multirow[b]{2}{*}{ Pitch } & \multirow[b]{2}{*}{ Speed } & \multirow{2}{*}{$\begin{array}{l}\text { FOV } \\
(\mathrm{cm})\end{array}$} & \multirow[b]{2}{*}{$k V p$} & \multicolumn{3}{|c|}{ Auto $\mathrm{mA}$} & \multirow{2}{*}{$\begin{array}{l}\text { Rotation } \\
\text { Time }\end{array}$} & \multirow{2}{*}{$\begin{array}{l}\text { Section } \\
\text { Thickness }\end{array}$} & \multirow{2}{*}{$\begin{array}{l}\text { Reconstruction } \\
\text { Interval }\end{array}$} & \multirow{2}{*}{$\begin{array}{l}\text { Prep } \\
\text { Group }\end{array}$} & \multirow[b]{2}{*}{ Amount } & \multirow{2}{*}{$\begin{array}{l}\text { Saline } \\
\text { Flush }\end{array}$} & \multirow[b]{2}{*}{ Rate } \\
\hline & & & & & & & Min & Max & $\mathrm{NI}$ & & & & & & & \\
\hline & Helical & $64 \times 0.625$ & $0.984: 1$ & 49.21 & 18 & 120 & 100 & 200 & 9 & 0.8 & 0.625 & 0.5 & - & - & - & - \\
\hline
\end{tabular}

Note:-Min, minimum; Max, maximum; -, not applicable.

\begin{tabular}{|c|c|c|c|c|c|c|c|c|c|c|c|c|c|c|c|c|}
\hline \multicolumn{17}{|c|}{ Thoracic and lumbar spine CT protocol } \\
\hline \multirow[b]{2}{*}{ Series } & \multirow{2}{*}{$\begin{array}{l}\text { Scan } \\
\text { Type }\end{array}$} & \multirow{2}{*}{$\begin{array}{c}\text { Detector } \\
\text { Configuration }\end{array}$} & \multirow[b]{2}{*}{ Pitch } & \multirow[b]{2}{*}{ Speed } & \multirow{2}{*}{$\begin{array}{l}\text { FOV } \\
(\mathrm{cm})\end{array}$} & \multirow[b]{2}{*}{$\mathrm{kVp}$} & \multicolumn{3}{|c|}{ Auto $\mathrm{mA}$} & \multirow{2}{*}{$\begin{array}{l}\text { Rotation } \\
\text { Time }\end{array}$} & \multirow{2}{*}{$\begin{array}{c}\text { Section } \\
\text { Thickness }\end{array}$} & \multirow{2}{*}{$\begin{array}{c}\text { Reconstruction } \\
\text { Interval }\end{array}$} & \multirow{2}{*}{$\begin{array}{l}\text { Prep } \\
\text { Group }\end{array}$} & \multirow[b]{2}{*}{ Amount } & \multirow{2}{*}{$\begin{array}{l}\text { Saline } \\
\text { Flush }\end{array}$} & \multirow[b]{2}{*}{ Rate } \\
\hline & & & & & & & Min & Max & $\mathrm{NI}$ & & & & & & & \\
\hline & Helical & $64 \times 0.625$ & $1.375: 1$ & 68.75 & 18 & 120 & 150 & 250 & 12 & 0.8 & 2.5 & 2 & - & - & - & - \\
\hline
\end{tabular}

Note:-Min, minimum; Max, maximum; -, not applicable.

our dose-reduction strategies described in the body of the review.

\section{References}

1. Kalra MK, Maher MM, Toth TL, et al. Strategies for CT radiation dose optimization. Radiology 2004;230:619-28

2. Berrington de Gonzalez A, Darby S. Risk of cancer from diagnostic X-rays: estimates for the UK and 14 other countries. Lancet 2004;363:345-51

3. Imhof $\mathrm{H}$, Schibany $\mathrm{N}, \mathrm{Ba}-\mathrm{Ssalamah} \mathrm{A}$, et al. Spiral CT and radiation dose. Eur J Radiol 2003;47:29-37

4. Mayo JR, Aldrich J, Muller NL. Radiation exposure at chest CT: a statement of the Fleischner Society. Radiology 2003;228:15-21

5. Wiest PW, Locken JA, Heintz PH, et al. CT scanning: a major source of radiation exposure. Semin Ultrasound CT MR 2002;23:402-10

6. Aroua A, Burnand B, Decka I, et al. Nation-wide survey on radiation doses in diagnostic and interventional radiology in Switzerland in 1998. Health Phys 2002;83:46-55

7. Linton OW, Mettler F Jr. National conference on dose reduction in CT, with an emphasis on pediatric patients. AJR Am J Roentgenol 2003;181:321-29

8. Associated Press (July 7, 2005). Low-Dose Radiation Levels Pose Cancer Risk. Available at: http://www.msnbc.msn.com/id/8389834/page/2/. Accessed December 15, 2006

9. Brenner D, Elliston C, Hall E, et al. Estimated risks of radiation-induced fatal cancer from pediatric CT. AJR Am J Roentgenol 2001;176:289-96

10. Feigal DW Jr. FDA public health notification: reducing radiation risk from computed tomography for pediatric and small adult patients. Int J Trauma Nurs 2002;8:1-2

11. McCollough CH, Bruesewitz MR, McNitt-Gray MF, et al. The phantom portion of the American College of Radiology (ACR) computed tomography (CT) accreditation program: practical tips, artifact examples, and pitfalls to avoid. Med Phys 2004;31:2423-42 
12. McNitt-Gray MF. AAPM/RSNA physics tutorial for residents: topics in CTradiation dose in CT. Radiographics 2002;22:1541-53

13. Imhof $\mathrm{H}$, Schibany $\mathrm{N}, \mathrm{Ba}-\mathrm{Ssalamah} \mathrm{A}$, et al. Spiral $\mathrm{CT}$ and radiation dose. Eur J Radiol 2003;47:29-37

14. Hamberg LM, Rhea JT, Hunter GJ, et al. Multi-detector row CT: radiation dose characteristics. Radiology 2003;226:762-72

15. Wintermark M, Maeder P, Verdun FR, et al. Using $80 \mathrm{kVp}$ versus $120 \mathrm{kVp}$ in perfusion CT measurement of regional cerebral blood flow. AJNR Am J Neuroradiol 2000;21:1881-84

16. Mastora I, Remy-Jardin M, Delannoy V, et al. Multi-detector row spiral CT angiography of the thoracic outlet: dose reduction with anatomically adapted online tube current modulation and preset dose savings. Radiology 2004;230:116-24

17. Kalra MK, Rizzo S, Maher MM, et al. Chest CT performed with z-axis modulation: scanning protocol and radiation dose. Radiology 2005;237:303-08

18. Mulkens TH, Bellinck P, Baeyaert M, et al. Use of an automatic exposure control mechanism for dose optimization in multi-detector row CT examinations: clinical evaluation. Radiology 2005;237:213-23
19. Kalra MK, Maher MM, D'Souza RV, et al. Detection of urinary tract stones at low-radiation-dose CT with z-axis automatic tube current modulation: phantom and clinical studies. Radiology 2005;235:523-29

20. Namasivayam S, Kalra MK, Pottala KM, et al. Optimization of Z-axis automatic exposure control for multidetector row $\mathrm{CT}$ evaluation of neck and comparison with fixed tube current technique for image quality and radiation dose. AJNR Am J Neuroradiol 2006;27:2221-25

21. Smith AB, Dillon WP, Lau BC, et al. Successful implementation of a radiation dose reduction strategy for CT protocols in a neuroradiology section. Radiology (in process)

22. Kalra MK, Wittram C, Maher MM, et al. Can noise reduction filters improve low-radiation-dose chest CT images? Pilot study. Radiology 2003;228:257-64

23. Kalra MK, Maher MM, Sahani DV, et al. Low-dose CT of the abdomen: evaluation of image improvement with use of noise reduction filters: pilot study. Radiology 2003;228:251-56 